\title{
Quantification of Excitatory Amino Acid Uptake at Intact Glutamatergic Synapses by Immunocytochemistry of Exogenous D-Aspartate
}

\author{
Vidar Gundersen, ${ }^{1}$ Oleg Shupliakov, ${ }^{2}$ Lennart Brodin, ${ }^{2}$ Ole Petter Ottersen, ${ }^{1}$ and Jon Storm-Mathisen ${ }^{1}$ \\ 'Anatomical Institute, University of Oslo, Blindern, N-0317 Oslo, Norway and ${ }^{2}$ The Department of Neuroscience, \\ Karolinska Institutet, S-17177 Stockholm, Sweden
}

To study the localization and efficiency of glutamate/aspartate membrane transport in the vicinity of intact glutamatergic synapses, the avascular lamprey spinal cord was incubated with D-aspartate, a metabolically inert transporter substrate. The exogenous D-aspartate was localized by immunocytochemistry after aldehyde fixation.

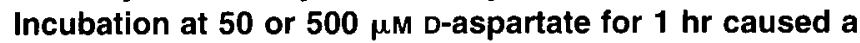
prominent $\mathrm{D}$-aspartate labeling of glial processes at glutamatergic synapses, while presynaptic axons and postsynaptic dendrites remained unlabeled. The glial processes surrounding glutamatergic sensory axons with a predominantly tonical firing pattern contained significantly higher levels of D-aspartate than did processes surrounding glutamatergic reticulospinal axons, which fire rarely and in brief bursts. Preparations incubated for $10 \mathrm{hr}$ with $500 \mu \mathrm{M}$ D-aspartate showed D-aspartate immunolabeling in glia as well as in the two types of glutamatergic axon, but no evidence was obtained for uptake into synaptic vesicles. Nor was such evidence obtained after high-frequency electrical stimulation.

The observations suggest that excitatory amino acids delivered diffusely to the extracellular space in the intact CNS are transported almost exclusively into glia. The avid uptake in glial processes, combined with their spatial arrangement around glutamatergic synapses, appears to IImit the access of exogenous D-aspartate to the nerve terminal glutamate/aspartate transporter. In physiological conditions, the glial processes are likely to impede the exchange of glutamate between the synaptic cleft and the rest of the extracellular space. The transport was more efficient in glial processes located near tonically active synapses than in ones located near synapses releasing transmitter sporadically. D-Aspartate is not a substrate of vesicular glutamate transport sites at these intact synapses.

[Key words: immunocytochemistry, D-aspartate uptake, neurons, glia, synaptic vesicles, lamprey spinal cord]

For normal brain function, the extracellular level of glutamate (Glu) must be maintained at low levels to avoid inappropriate stimulation of Glu receptors and to prevent excitotoxic effects

\footnotetext{
Received Aug. 25, 1994; revised Jan. 19. 1995: accepted Jan 20. 1995.

We thank Anna Torbjorg Bore. Bjorg Riber. Gunnar Lothe, and Kari Ruud for assistance. This work was supported by the Norwegian Research Council and by the Swedish Medical Research Council (Grant 10378).

Correspondence should be addressed to Vidar Gundersen. Anatomical Instime. University of Oslo, P.O. Box 1105, Blinderll. N-0317 Oslo, Non way.

Copyright@1995 Society for Neuroscience (270-6474/95/154417-12\$05.00/0
}

(McBean and Roberts, 1984; Garthwaite et al., 1992). Although it is generally agreed that Glu transporters occur in glial (Danbolt et al., 1992; Storck et al., 1992) as well as in neuronal (Kanai and Hediger, 1992; Gundersen et al., 1993; Kanai et al., 1994) plasma membranes, the relative importance of the glial and neuronal transport in maintaining the extracellular glutamate level is as yet unclear. This issue is central to understanding the pathophysiology of disease states in which Glu excitotoxicity plays a role.

Several studies have attempted to localize excitatory amino acid uptake by incubating acutely prepared slices of mammalian brain (Storm-Mathisen and Iversen, 1979; Wilkin et al., 1982; Taxt and Storm-Mathisen, 1984: Garthwaite and Garthwaite. 1985; Gundersen et al., 1993). However, it is unclear to what an extent transport in a slice preparation reflects that in the intact brain. In slice preparations, the glial processes and the extracellular space show volume changes, which distort the spatial relationships between glial and neuronal elements and make interpretation difficult. Furthermore, most previous studies have relied on autoradiographic localization of the transported substrate. The anatomical resolution of this method is limited, as the track length of the $\beta$-particles emitted from the radiolabeled tracer is in the order of several micrometers.

Analysis of the role of glial and neuronal elements in the uptake of glutamate and other excitatory amino acids will require both a preparation in which the synaptic structure is preserved and a method to localize the uptake activity with a high anatomical resolution. The present study uses the lamprey spinal cord as a model to localize the uptake of I-aspartate (D-Asp), a metabolically inert substrate of plasma membrane Glu/Asp transporters (Davies and Johnston, 1976). (All known Glu transporters, whether glial or neuronal, carry D- and L-Asp as well as L-Glu (Kanai and Hediger, 1992; Pines et al., 1992; Storck et al., 1992).) To detect D-Asp in the fixed tissue, an antiserum toward fixation products of D-Asp (Gundersen et al., 1993; Zhang et al., 1993) was used with the postembedding immunogold technique, which gives a highly specific signal with a resolution of about 20-25 $\mathrm{nm}$ (Ottersen, 1989).

The avascular lamprey spinal cord is well suited for this type of analysis, as it can be maintained under in vitro conditions for about $2 \mathrm{~d}$ with preserved physiological and morphological characteristics (for review, see Brodin and Grillner, 1990). This preparation also provides the opportunity to compare the uptake in different types of glutamatergic synapse with distinct properties. The ventromedial spinal cord contains the giant reticulospinal (Müller) axons, which are mostly silent in the living animal, and 


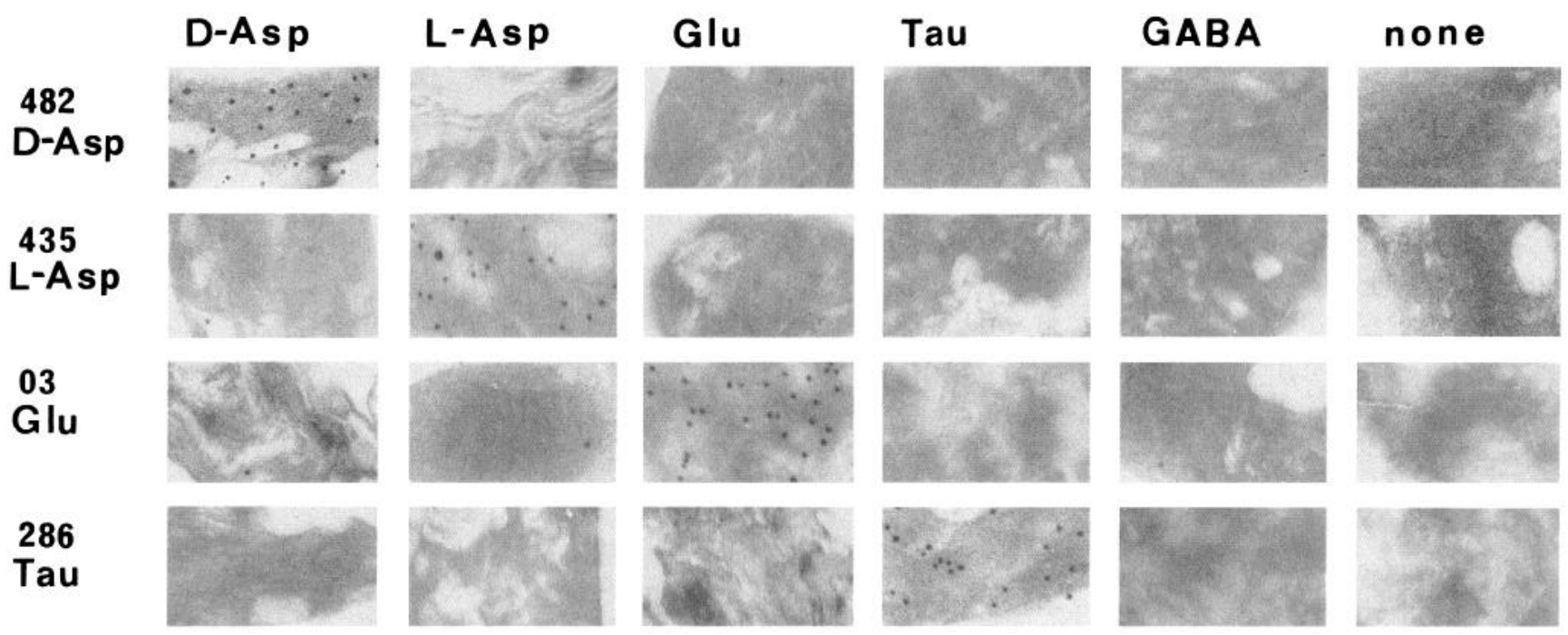

Figure 1. Electron micrographs of ultrathin sections of test conjugates processed with the antisera 482 D-Asp, 435 L-Asp, 03 Glu, and 286 Tau. The test sections were exposed to the antisera on one side, along with the ultrathin tissue sections presented in Figure 9 . All antisera were preabsorbed with soluble glutaraldehyde/formaldehyde complexes of various amino acids (see Materials and Methods). The conjugates were prepared by coupling D-Asp, L-Asp, L-Glu, Tau, GABA, Gly, L-Gln, L-Asn, L-Cys, and L-homocysteic acid (only the former five shown here; compare Fig. 4, inset) to brain macromolecules by glutaraldehyde or glutaraldehyde/formaldehyde before freeze drying and embedding in epoxy resin. In order to obtain a high sensitivity to cross-reactivities, the conjugates contained high (about $100 \mathrm{mmol} / \mathrm{l}$ ) final concentrations of amino acids. The antisera selectively labeled the conjugate containing the amino acid used for immunization. none, no amino acids in reaction mixture.

fire in brief bursts to mediate steering and escape commands (cf. Brodin and Grillner, 1990). The dorsal column contains another group of glutamatergic axons, of which most exhibit a tonic firing at high rate (Christenson et al., 1987a,b). In both types of axon, the clusters of synaptic vesicles are distinctly separated

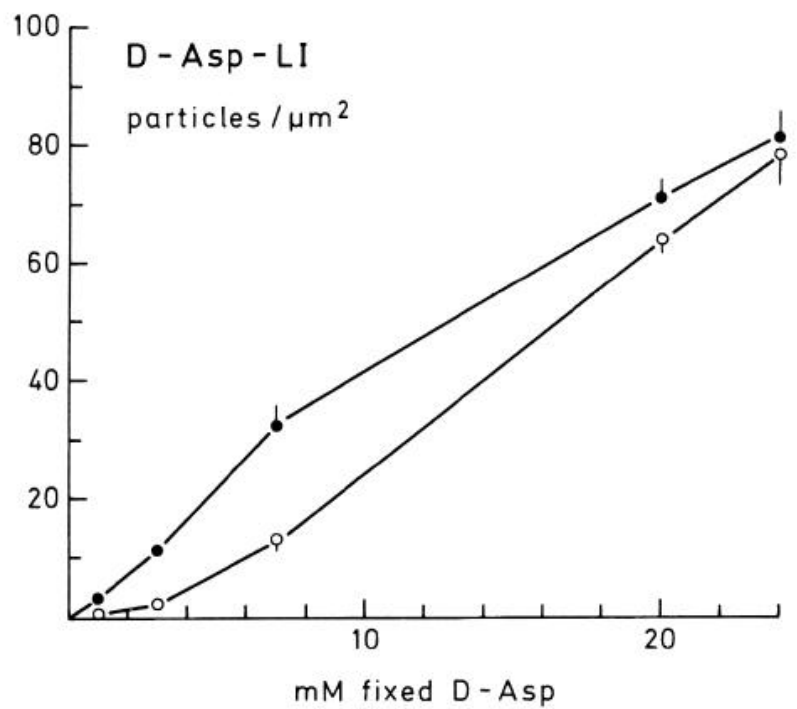

Figure 2. D-Aspartate-like immunoreactivity (gold particles $/ \mu \mathrm{m}^{2}$ ) as a function of the concentration of fixed D-Asp in the graded test conjugates $(\mathrm{mmol} / \mathrm{l})$ is nearly linear. The curve with open circles is determined from graded test sections run along with the tissue sections shown in Figure 5, the curve with filled circles is from the experiment shown in Figure 7. Each point gives the mean density of gold particles \pm SEM calculated over conjugates in four to five electron micrographs. Background labeling over empty resin $\left(0.3-0.5\right.$ particles $\left./ \mu \mathrm{m}^{2}\right)$ was subtracted. The graded conjugates were made from slabs of gelatin containing human serum albumin, which were equilibrated with different concentrations of D-Asp before fixation with glutaraldehyde/formaldehyde and embedding in Durcupan. The concentrations of D-Asp in the slabs after fixation were determined from tracer D- ${ }^{3} \mathrm{H}$-Asp. from the surrounding axoplasmic matrix, which makes it possible to examine the handling of D-Asp subsequent to its uptake through the plasma membrane. In particular, whether D-Asp can accumulate in synaptic vesicles in the intact synapse (cf. isolated synaptic vesicles, Naito and Ueda, 1983), as indicated by its rapid axonal transport (Brodin et al., 1989) is of direct relevance to the transmitter status of Asp.

\section{Materials and Methods}

The in vitro lamprey spinal cord preparation. Adult lampreys (Lampetra fluvatilus) were anesthetized by immersion in a solution of tricaine methane sulphonate (MS-222; $100 \mathrm{mg} / \mathrm{liter}$ water). The spinal cord with notochord was dissected in physiological solution with the following composition (mM): $\mathrm{NaCl}, 91 ; \mathrm{KCl}, 2.1 ; \mathrm{CaCl}_{2}, 2.6 ; \mathrm{MgCl}_{2}, 1.8$; glucose, 4; $\mathrm{NaHCO}_{3}, 20$. The solution was bubbled with $95 \% \mathrm{O}_{2}$ and $5 \% \mathrm{CO}_{2}$ to $\mathrm{pH} 7.4\left(8^{\circ} \mathrm{C}\right)$. Pieces of spinal cord $(60-70 \mathrm{~mm}$ long) were incubated at $6^{\circ} \mathrm{C}$ in physiological solution containing different concentrations of D-Asp with or without taurine (Tau) as follows: (1) at $50 \mu \mathrm{M}$ D-Asp for $1 \mathrm{hr}$, (2) at $500 \mu \mathrm{M}$ D-Asp for $1 \mathrm{hr}$ or $10 \mathrm{hr}$, (3) at $500 \mu \mathrm{M}$ D-Asp plus $500 \mu \mathrm{M}$ Tau for $10 \mathrm{hr}$. For each experiment a piece of spinal cord was incubated in physiological solution without D-Asp (1 hr and $10 \mathrm{hr}$ ) to serve as control. Although diffusion of amino acids through the cut ends of lamprey axons appears to be limited $(\mathrm{O}$. Shupliakov and $\mathrm{V}$. Gundersen, unpublished observations), the cut ends were blotted with filter paper and covered with vaseline prior to incubation to avoid possible leakage of exogenous D-Asp. In one experiment, the specimens were incubated at $500 \mu \mathrm{m}$ D-Asp for $10 \mathrm{hr}$ before electrical stimulation of the spinal axons with bipolar electrodes at $20 \mathrm{~Hz}$ for $15 \mathrm{~min}$ (see Wickelgren et al., 1985). To obtain a selective stimulation of the axons on one side, the spinal cord was hemisected just caudal to the stimulating electrode. The efficiency of the stimulation was monitored by recording the spike volleys in the caudal end of the preparation. The period of stimulation was followed by a period of rest for $30 \mathrm{~min}$ before fixation. Throughout the experiment $500 \mu \mathrm{M}$ D-Asp was present in the bathing solution.

Fixation and immunocytochemical procedures. The spinal cords were fixed in a solution of $2.5 \%$ glutaraldehyde and $1 \%$ formaldehyde in 0.1 M sodium phosphate buffer ( $\mathrm{pH} 7.4$ ), and kept overnight in $0.25 \%$ glutaraldehyde and $0.1 \%$ formaldehyde in the same buffer at $4^{\circ} \mathrm{C}$. Three to four segments from the middle part of the preparation were cut out for further analysis. Previous experiments have shown that postfixation in $\mathrm{OsO}_{4}$ gives a poor visualization of D-aspartate-like immunoreactivity 
A

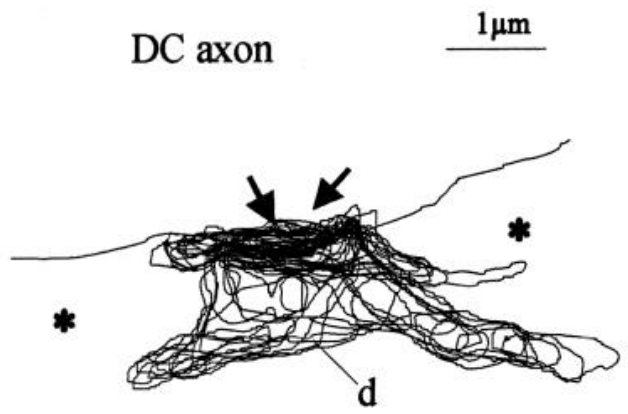

B

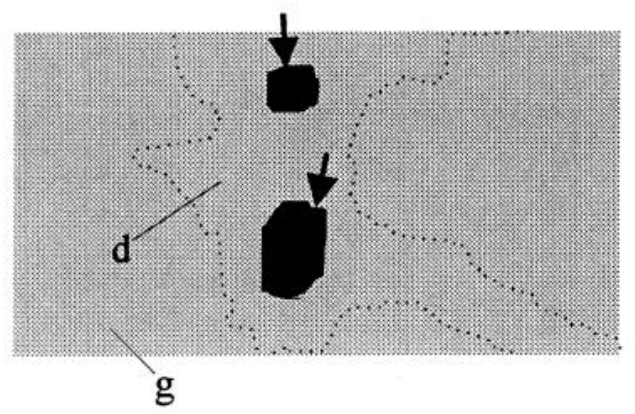

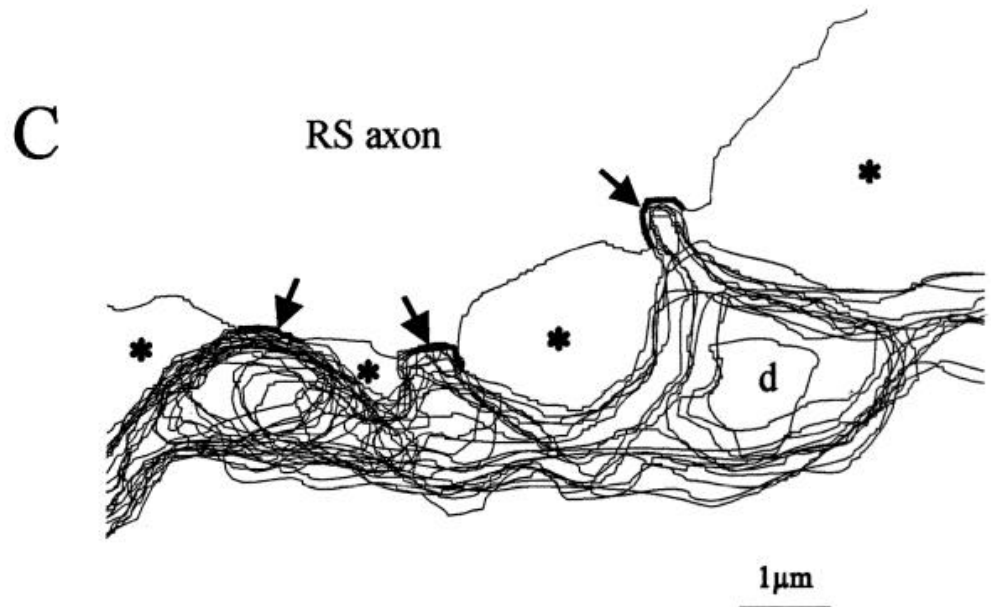

$\mathrm{D}$

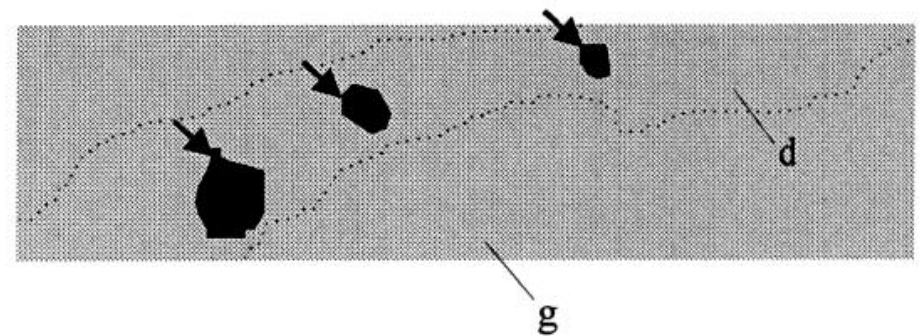

Figure 3. Organization of pre- and postsynaptic elements and glial cell processes in glutamatergic synapses in the lamprey spinal cord. $A-D$ show three-dimensional reconstructions of dendritic shafts $(d)$ receiving synapses from a dorsal column axon $(A$ and $B ; D C$ axon) and a reticulospinal axon ( $C$ and $D ; R S$ axon), respectively. The sites of synaptic contact have been indicated with arrows. The surface of the axon has been drawn from one section in the middle of the series of sections in each case (synaptic vesicle clusters have not been included). The glial processes occupy the entire space (marked with asterisks) in between the dendritic shafts and the surface of the axons. $A$ and $C$ show the reconstruction as seen vertical to the plane of cutting (i.e., a view from rostral to caudal). $B$ and $D$ show $90^{\circ}$ rotations, giving a view from dorsal to ventral. The glial profiles $(g)$ occupy the entire shaded area. Note that the shaded area of glial processes completely surrounds the areas of synaptic contact between axon and dendrite (dark areas indicated with arrows). The position of the dendritic shafts, which are obscured by glial cell processes, has been indicated with dashed lines in $B$ and $D$. The surfaces of the axons have not been included in this rotation. Scale bar, $1 \mu \mathrm{m}$.

(D-Asp-LI) (Gundersen et al., 1993). The spinal cords were therefore rinsed in $0.3 \mathrm{~mm}$ sodium acetate and treated for $1 \mathrm{hr}$ with $2 \%$ uranyl acetate in $0.15 \mathrm{M}$ acetate buffer $(\mathrm{pH} 6.0)$ on ice, before dehydration in ethanol and embedding in Durcupan ACM. Semithin $(0.5 \mu \mathrm{m})$ and ultrathin $(50-100 \mathrm{~nm})$ sections were mounted on glass slides and nickel grids and processed with the antibodies according to a streptavidinbiotin-peroxidase (Hsu et al., 1981) and an immunogold method (Somogyi et al., 1986; Ottersen, 1987; 1989), respectively. The following antisera were used (dilution semithin sections/dilution ultrathin sections): 482 D-Asp (1:500/1:200), 435 L-Asp (1:800/1:300), 03 L-Glu (1:500/1:100), and 286 Tau (1:3000/1:1500). The semithin sections were incubated with the antibodies overnight at $4^{\circ} \mathrm{C}$, whereas the ultrathin sections were immunolabeled on one or both sides at $20-30^{\circ} \mathrm{C}$ for 3-4 hr. The antibodies were raised essentially as originally described (Storm-Mathisen et al., 1983) by immunizing rabbits against fixation complexes of the various amino acids coupled to bovine serum albumin by glutaraldehyde (antiserum 03) or glutaraldehyde-formaldehyde (antisera $482,435,286)$ in the same weight proportion $(2.5: 1)$ as for tissue fixation. All sera have been extensively characterized and proven highly specific: 482 (Gundersen et al., 1993; Zhang et al., 1993), 435 (Zhang et al., 1993), 03 (Ji et al., 1991; Davanger et al., 1994), 286 (Zhang and Ottersen, 1992; Amiry-Moghaddam et al., 1994). In order to ensure that no cross-reactivity occurred, the antisera were preadsorbed by adding $0.2 \mathrm{~mm}$ of soluble glutaraldehyde-formaldehyde $(\mathrm{G} / \mathrm{F})$ complexes, to the diluted sera $3-12 \mathrm{hr}$ before performing the experiments, as follows: L-Asp-G/F and L-Glu-G/F were added to the D-Asp antibodies; L-GluG/F, D-Asp-G/F, L-asparagine-G/F, and GABA-G/F to the L-Asp anti- bodies; L-Asp-G/F and L-glutamine-G/F to the L-Glu antibodies; and L-Glu-G/F and $\beta$-alanine-G/F to the Tau antibodies.

Specificity controls. As a specificity, control for each experiment sections with test antigens accompanied the semithin and ultrathin tissue sections. Briefly, different amino acids were reacted with brain macromolecules (i.e., chiefly protein) by glutaraldehyde or by a glutaraldehyde/ formaldehyde mixture, dialyzed, freeze dried, embedded in Durcupan, and sectioned at $0.5 \mu \mathrm{m}$ or $50-100 \mathrm{~nm}$ (Ottersen, 1987, 1989). The concentrations of fixed amino acids in the electron dense aggregates (Fig. 1) is about $100 \mathrm{~mm}$ (Ottersen, 1989). Blocking experiments were performed by adding $0.3 \mathrm{~mm}$ of $\mathrm{G} / \mathrm{F}$ complexes (Dale et al., 1986) of the amino acid used for immunization to the antisera before they were applied to the tissue sections and test sections. Spinal cords incubated without D-Asp served as an additional negative control for the D-Asp antibodies.

Graded test sections. In order to estimate the relationship between D-Asp immunogold particle density and antigen concentration in the tissue, graded test sections containing different concentrations of fixed D-Asp were run along with the ultrathin tissue sections. These conjugates were made by gelling slabs of $7 \%$ gelatin and $10 \%$ human serum albumin (HSA) between precision glass plates separated by $0.65 \mathrm{~mm}$ spacers. By use of a dissection microscope with a micrometer eye-piece blocks of rectangular shape and known areas were cut out of the slabs and incubated in 10\% HSA at various concentrations of D-Asp $(0,1,3,10,30$, 100 , and $300 \mathrm{~mm}$ ) before immersing in the tissue fixative for $1 \mathrm{hr}$. These fixed blocks were thereafter subjected to the same treatment as the fixed tissue and finally embedded in Durcupan (see above). The concentrations of D-Asp in the conjugate slabs after fixation (but before embedding) 


\section{D-Asp-LI}

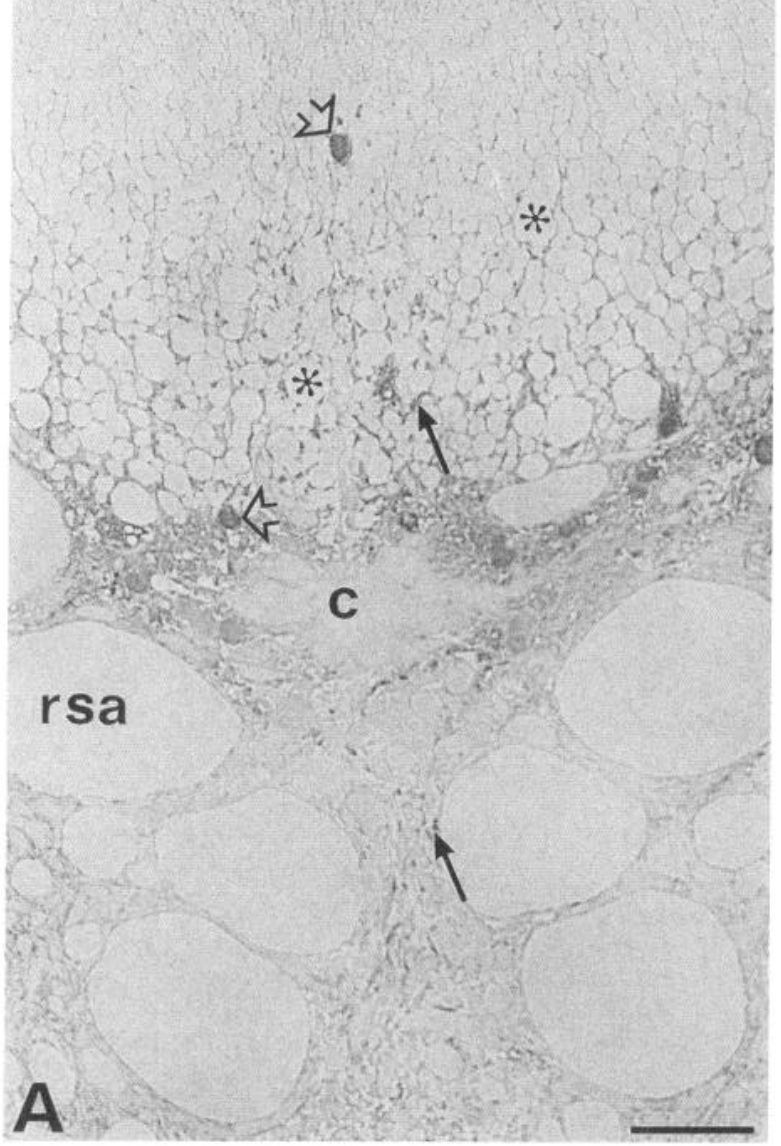

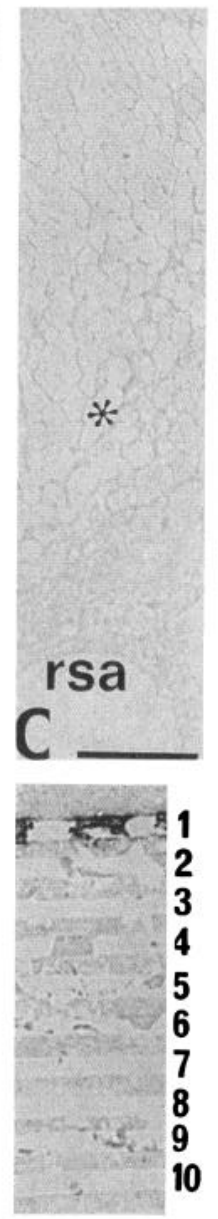

Figure 4. Semithin sections $(0.5 \mu \mathrm{m})$ of a lamprey spinal cord incubated with $50 \mu \mathrm{M}$ D-Asp for 1 hr $(A$ and $D)$, and of a specimen incubated with $500 \mu \mathrm{M}$ D-Asp for $10 \mathrm{hr}(B$ and $E$ ). The spinal cord shown in $C$ was incubated for $10 \mathrm{hr}$ without D-Asp. The sections in $A-D$ were labeled with the D-Asp antiserum; the one in $E$ was stained with the Glu antiserum. $A$ and $D$, Note that only glial processes (arrows) and glial cell bodies (open arrows) were labeled. Reticulospinal axons ( $r s a$ ) and dorsal column axons (asterisks) were devoid of immunoreactivity. The section shown in $D$ is some distance away from the one shown in A. B. Accumulation of D-Asp-LI in glial processes (arrows) and glial cell bodies (open arrows) as well as in reticulospinal axons ( $r s a)$ and dorsal column axons (asterisks). Note the lack of D-Asp staining of vesicle clusters, evident with the Glu antibodies (arrowheads in E). C, Note the absence of specific immunostaining of tissue not exposed to D-Asp. (The section was lightly counterstained with $0.1 \%$ toluidine blue). Inset (between $C$ and $D$ ), semithin test section (incubated along with the tissue sections in $A-C$ ). The numbers indicate the different amino acid conjugates: 1, D-Asp; 2, D-homocysteic acid; 3, L-Asp; 4, L-homocysteic acid; 5, L-Asn; 6, L-Cys; 7, L-Glu; 8, L-Gln; 9, D-Cys; 10, none. Note that only the D-Asp conjugate is labeled. $c$, central canal. Scale bar, $40 \mu \mathrm{m}$.

were determined by liquid scintillation counting using tracer amounts of D- ${ }^{3} \mathrm{H}-\mathrm{Asp}$. In this way the particle density in tissue compartments could be compared to those over the different D-Asp conjugates. In one experiment, graded L-Asp, L-Glu, and Tau sections prepared as described before (Ottersen, 1989) accompanied the tissue sections.

Structures studied. Electron micrographs (Philips CM10) at $\times 6300$ primary magnification $(\times 47500$ final $)$ were taken from the ventral and dorsal parts of the spinal cord. Gold particles were counted over the following cellular components: (1) synaptic vesicle clusters of reticulospinal (Müller) axons and dorsal column axons, (2) axoplasmic matrix surrounding the vesicle clusters in the two types of axon, (3) dendrites postsynaptic to reticulospinal axons and dorsal column axons, (4) glial processes in contact with the synapses made by reticulospinal axons and by dorsal column axons, and (5) glial cell bodies. Reticulospinal axons and dorsal column axons were identified as described previously (Shupliakov et al., 1992; see also Peters et al., 1991). In tissue incubated for $10 \mathrm{hr}$, only axons containing D-Asp concentrations exceeding $1 \mathrm{~mm}$ (as estimated from the accompanying graded sections) were included in the study. Glial processes and cell bodies were identified by the presence of glial filaments.

The area of the defined tissue profiles and the glial process boundary length per profile area were determined by counting points and line intersections, respectively, using an overlay screen (Gundersen et al.,
1988). Particle densities over the various cellular and subcellular structures produced by the different antisera were calculated.

In tissue incubated with $50 \mu \mathrm{M}$ D-Asp, gold particles were also counted over fascicles of filaments in glial processes surrounding reticulospinal axon and dorsal column axon synapses. The area occupied by filaments in the fascicles, the total fascicle area, and the area outside the filament fascicles in the processes were estimated by point counting (see above). The number of D-Asp immunogold particles was determined per filament area in the two types of glial process. All data were statistically evaluated by the Mann-Whitney $U$ test (two tails).

Materials. Uranyl acetate and Durcupan ACM were from Fluka (Buchs, Switzerland), glutaraldehyde (25\%, EM and practical grade) and paraformaldehyde from TAAB (Reading, UK), and Soluene 250 and Hionic Fluor from Packard (Meriden). D-Aspartate and Tau were obtained from Sigma (St. Louis, MO). D- ${ }^{3} \mathrm{H}-\mathrm{Asp}(30 \mathrm{Ci} / \mathrm{mmol})$, antirabbit Ig (biotinylated Ig from goat), streptavidin-biotinylated horseradish peroxidase complex, and Auroprobe $15 \mathrm{GAR}$ were purchased from Amersham (UK).

\section{Results}

Antibody specificity

All antisera selectively labeled the test conjugate containing the amino acid against which the antiserum was raised (Fig. 1; for 

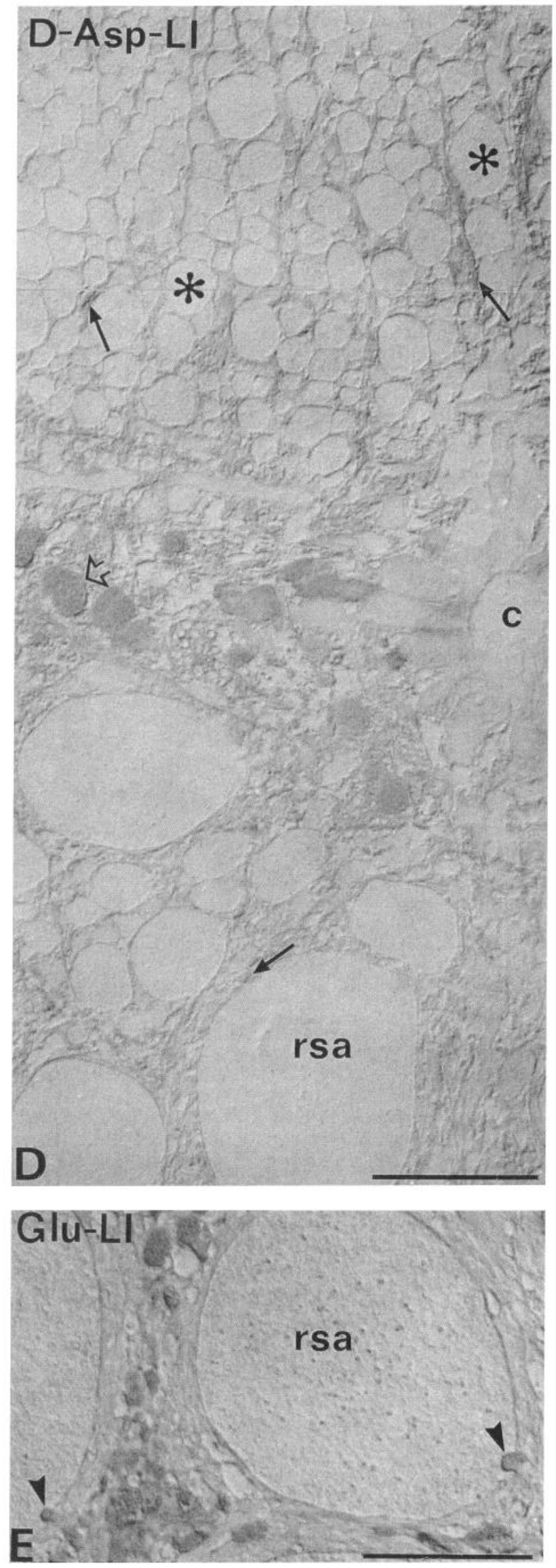

Figure 4. Continued. semithin sections processed with the D-Asp antibodies, see inset in Fig. 4). Furthermore, the addition of G/F complexes of the amino acid against which the serum was raised abolished the immunostaining of tissue and test sections. Tissue incubated without D-Asp did not display D-Asp-LI in the light microscope (see Fig. $4 B$ ), and only $0.7 \pm 0.1$ gold particles $/ \mu \mathrm{m}^{2}$ (mean \pm SEM in five experiments) in parallel immunogold preparations. This value, recorded over neuropil in the dorsal and ventral cord, is similar to the background particle density over tissue-free resin.

\section{Relationship between gold particle density and antigen concentration}

Labeling of sections containing a graded series of concentrations of the amino acids D-Asp (Fig. 2), L-Asp, Glu, and Tau (not shown) demonstrated a nearly linear relationship between the antigen concentrations and the gold particle densities produced by the different antisera. As the slope may vary between the individual immunogold experiments (Fig. 2, filled circles vs open circles), the graded sections were only used to infer about the amino acid concentrations in the accompanying tissue sections. The labeling of the graded sections suggested that the D-Asp immunogold method as used here did not detect concentrations of fixed D-Asp in the tissue that were below $0.5-1 \mathrm{~mm}$.

\section{Structural organization of synaptic regions of reticulospinal and dorsal column axons}

To determine the structural relation between the different elements in reticulospinal and dorsal column synapses 10 serially sectioned synapses of each type were analyzed. Figure 3 shows serial section reconstructions including the boundaries of dendrites and glial processes in the synaptic area of a dorsal column synapse (Fig. $3 A, B$ ) and a reticulospinal axon (Fig. $3 C, D$ ). The synaptic vesicle clusters are not included. In both cases, the synapses were formed between the main trunk of the axon and a protrusion from the postsynaptic dendrite, which could vary in shape from a thin spine-like structure to a small protuberance (sites of synaptic contacts are indicated by arrows). The synaptic clefts were surrounded by a collar of glial processes. Also, where several synapses were closely spaced, the individual active zones were separated from each other by glial processes (Figs. 3B,D). A similar organization of glial processes was observed at all synapses examined.

\section{Short-term incubation with D-aspartate}

After incubation of the spinal cord with $50 \mu \mathrm{M}$ or $500 \mu \mathrm{M}$ D-Asp for $1 \mathrm{hr}$, both the semithin and the ultrathin sections displayed D-Asp-like immunoreactivity (D-Asp-LI) (Figs. 4A, 5) in glial processes surrounding reticulospinal (Müller) and dorsal column axons, as well as in glial cell bodies. Both axon types as well as their postsynaptic dendrites were essentially unlabeled. Quantitative electron microscopy (Fig. 6) showed that the density of gold particles was significantly higher in glial processes surrounding synapses of dorsal column axons than in those surrounding reticulospinal axon synapses both at $50 \mu \mathrm{M}$ and 500 $\mu \mathrm{M}$ D-Asp. The particle density in the two types of process corresponded to concentrations of fixed D-Asp of about $5 \mathrm{~mm}$ and $4 \mathrm{~mm}$, respectively, following exposure to $50 \mu \mathrm{M}$ D-Asp, and about $10 \mathrm{~mm}$ and $8 \mathrm{~mm}$ following exposure to $500 \mu \mathrm{M}$ D-Asp.

To investigate whether differences in membrane surface per profile volume could underlie the different labeling intensity be- 

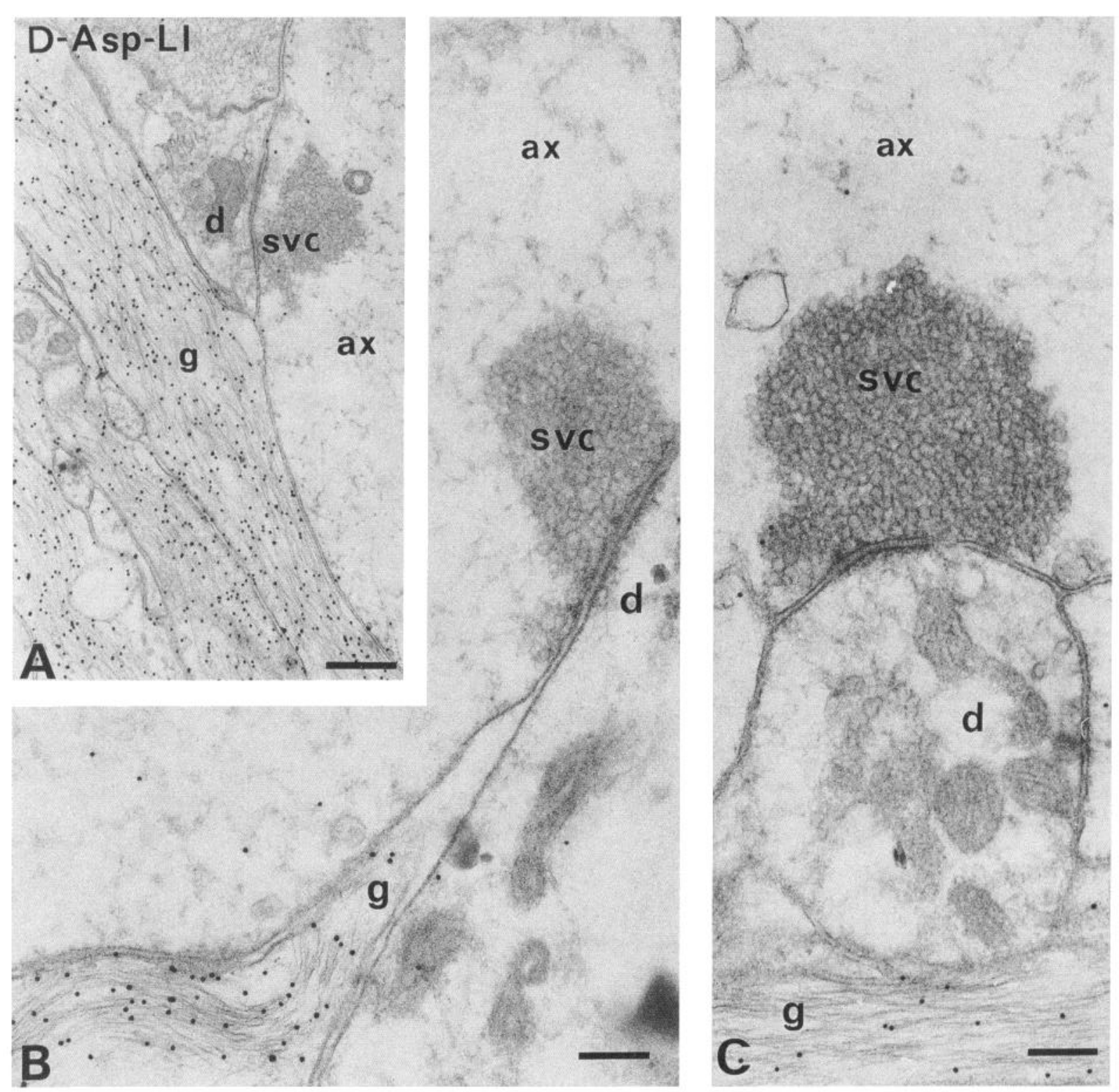

Figure 5. D-Aspartate-like immunoreactivity in glial processes surrounding dorsal column synapses $(A$ and $B)$ and a reticulospinal synapse $(C)$ in spinal cords incubated with $50 \mu \mathrm{M}$ D-Asp $(B$ and $C$ ) or $500 \mu \mathrm{M}$ D-Asp $(A)$ for $1 \mathrm{hr}$. Note that the enrichment of immunogold particles over the glial process $(g)$ contacting the dorsal column synapse is higher than in that adjacent to the reticulospinal synapse at $50 \mu \mathrm{M}$ D-Asp. Note also the higher labeling intensity in the glial processes at $500 \mu \mathrm{M}$ D-Asp. Axoplasmic matrix (ax), synaptic vesicle clusters ( $s v c)$, and postsynaptic dendrites (d) are virtually unlabeled. Scale bars: $A, 0.4 \mu \mathrm{m} ; B$ and $C, 0.2 \mu \mathrm{m}$.

tween the two types of glial process, the process boundary lengths per area of profile were determined. There was no significant difference (average about $10 \mu \mathrm{m}^{-1}$ in all cases).

Since glutaraldehyde causes amino acids to be retained by cross-linking them to proteins, variations in protein concentration could affect the labeling density. Indeed, individual glial profiles showed a positive correlation $(r=0.8, p<0.01)$ between the density of glial filaments and the density of D-Asp immunogold particles within the filament fascicles. This cannot, however, explain the observed differences in labeling intensity between the two categories of glial profiles, as the average glial filament density was the same in both (data not shown).

\section{Long-term loading with D-aspartate}

D-Aspartate-like immunoreactivity. To test whether axonal uptake could be detected after a longer incubation period, spinal cords were incubated with $500 \mu \mathrm{M}$ D-Asp for $10 \mathrm{hr}$. Except for occasional swelling of glial cells, the morphology of these specimens was well preserved (Figs. $4 B, 7,8$ ). After such long-term incubation, D-Asp-LI appeared in reticulospinal and dorsal column axons. Light microscopic observations (Fig. 4B) showed that within the axons D-Asp-LI was concentrated in small dots scattered throughout the axoplasm, and that there was no distinct accumulation of D-Asp-LI corresponding to that observed for Glu-LI over vesicle clusters (compare Fig. 4B,E). Electron microscopy revealed that the dots represented labeled mitochondria, and that synaptic vesicle clusters contained immunogold particles signalling D-Asp (Fig. 7). However, the gold particle ratios (vesicle cluster:axoplasmic matrix) were only 2.6:1 for reticulospinal axons and 1.1:1 for dorsal column axons (Fig. 9). This difference can partly be explained by the fact that the latter 


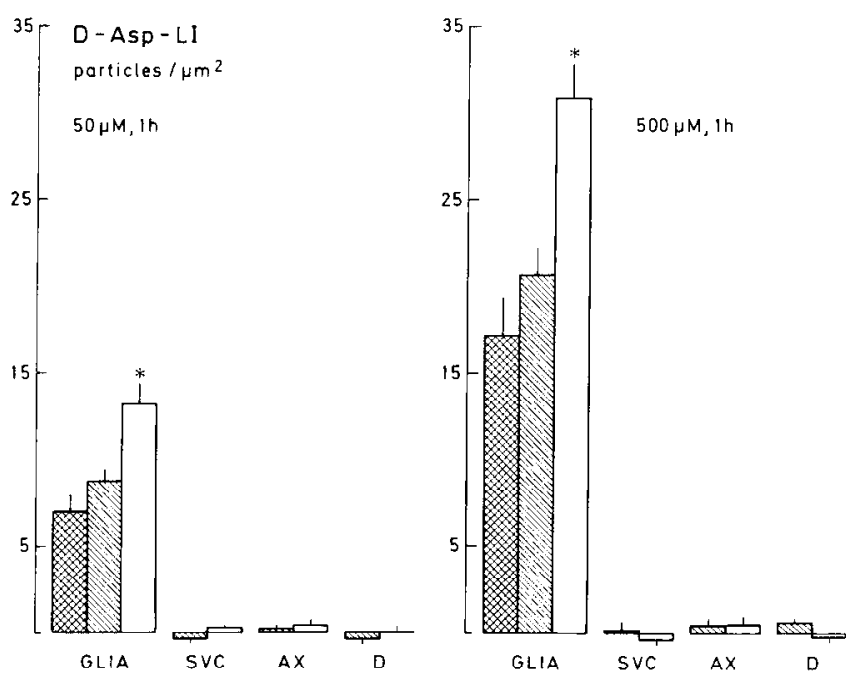

Figure 6. Quantitative determination of D-Asp-LI in various tissue compartments in specimens incubated with $50 \mu \mathrm{M}$ or $500 \mu \mathrm{M}$ D-Asp for $1 \mathrm{hr}$. The values are mean numbers of gold particles $/ \mu \mathrm{m}^{2} \pm \mathrm{SEM}$ (n tissue profiles) corrected for background immunoreactivity over empty resin $\left(0.5 \mathrm{particles} / \mu \mathrm{m}^{\prime}\right)$. The mean values are calculated by pooling data from three individual immunocytochemical experiments. Crosshatched columns give the mean density of gold particles in glial cell bodies. Hatched columns and open columns represent various cellular and subcellular profiles related to reticulospinal axon synapses and dorsal column axon synapses, respectively: GLIA, glial cell bodies and processes in contact with the pre- and/or postsynaptic element; $S V C$, synaptic vesicle clusters; $A X$, axoplasmic matrix around the vesicle clusters; $D$, postsynaptic dendrites. Asterisks indicate that the density of D-Asp immunogold particles in glial processes around dorsal column synapses at $50 \mu \mathrm{M}(n=65)$ and $500 \mu \mathrm{M}(n=20)$ D-Asp is significantly different from the density in processes surrounding reticulospinal synapses $(n=50$ and 20$)$ as well as in glial cell bodies $(n=10$ and 9$)$, $p<0.001$. Values in other compartments were not significantly different from the background labeling.

axons contain clusters with a lower density of synaptic vesicles (O. Shupliakov and L. Brodin, unpublished observations). The gold particle densities in axoplasmic matrix and in synaptic vesicle clusters in reticulospinal axons represented of the order of 2 and $4 \mathrm{~mm}$ fixed D-Asp, respectively. About $50 \%$ of the free amino acids seems to be retained by the aldehyde mixture used in the present study (Storm-Mathisen and Ottersen, 1990); thus, the free D-Asp concentration in the axoplasmic matrix was of the order of $4 \mathrm{~mm}$ prior to fixation (see Discussion). Postsynaptic dendrites showed a similar labeling intensity as the axoplasmic matrix.

Long-term incubation with exogenous D-Asp led to an intense labeling of glial processes (Figs. $4 B, 7$ ). The density of gold particles was significantly higher in glial processes around dorsal column synapses than in those surrounding reticulospinal synapses (Fig. 9), as after 1 hr incubation, but the absolute labeling intensity was about two to three times higher. The glial labeling corresponded to fixed D-Asp concentrations of approximately $20 \mathrm{~mm}$ and $24 \mathrm{~mm}$ at reticulospinal and dorsal column synapses, respectively.

Glutamate-like and L-aspartate-like immunoreactivities. The distribution of glutamate-like immunoreactivity (Glu-LI) in specimens incubated with D-Asp for $10 \mathrm{hr}$ was different from the D-Asp-LI pattern (Figs. $8 A, B ; 9$ ). The dorsal column axons were more intensely Glu immunopositive than the reticulospinal axons. In semithin light microscopic sections the latter axons displayed punctate Glu staining along the axon periphery (Fig.
$4 E$ ) which, at the electron microscopic level, corresponded to vesicle clusters. The Glu particle density over synaptic vesicle clusters exceeded that in axoplasmic matrix by a factor of 17 in reticulospinal axons and by a factor of 5.6 in dorsal column axons (Fig. 9).

The L-Asp antiserum produced similar labeling intensities in the reticulospinal axons as in the dorsal column axons, and synaptic vesicle cluster-like staining was not observed with the light microscope. Quantification of L-Asp-like immunoreactivity (LAsp-LI) gave ratios of gold particle density between synaptic vesicle clusters and axoplasmic matrix of 3.0 and 1.9 in reticulospinal and dorsal column axons, respectively.

Glial structures were weakly stained both with the Glu and L-Asp antisera (Fig. 9). The distributions of Glu-LI and L-AspLI in tissue incubated with D-Asp were the same as in tissue not exposed to D-Asp (not shown; cf. Shupliakov et al., 1992). Graded sections indicated that the average concentrations of fixed endogenous L-Glu and L-Asp were of the order of $12 \mathrm{~mm}$ and $3 \mathrm{~mm}$, respectively, in reticulospinal synaptic vesicle clusters, and $17 \mathrm{~mm}$ and $2 \mathrm{~mm}$ in dorsal column vesicle clusters (comprising vesicular and extravesicular space).

\section{Long-term loading with exogenous D-aspartate and taurine}

For comparative purposes, $500 \mu \mathrm{M}$ Tau was added to the incubation medium together with $500 \mu \mathrm{M} \mathrm{D}$-Asp. Taurine was chosen, as it is utilizing different plasma membrane transporters than D-Asp (Balcar and Johnston, 1972) and at the same time it is not thought to be taken up into synaptic vesicles (Christensen et al, 1991), nor thought to act as a transmitter in lamprey axons (Shupliakov et al., 1994). As for D-Asp-LI, analysis of semithin and ultrathin sections showed that glial profiles were more strongly Tau immunopositive than were neuronal elements, and that Tau-LI was higher in glial processes contacting dorsal column axons than in those contacting reticulospinal axons. The Tau labeling showed a 2.5 -fold accumulation over synaptic vesicle clusters in reticulospinal axons and a 1.9-fold accumulation in dorsal column axons. These values can be used as an index of the difference in fixation efficiency between vesicle clusters and axoplasmic matrix. From the graded Tau sections the approximate concentration of fixcd accumulated Tau in the different tissue compartments could be inferred ( $\mathrm{mm}$ ): axoplasmic matrix of reticulospinal and dorsal column axons (1.5), synaptic vesicle clusters of the two axon types (3), glial processes contacting dorsal column axon synapses (15) and glial processes contacting reticulospinal axon synapses (13).

The addition of Tau to the incubation medium did not alter the distribution of D-Asp-LI.

\section{D-Asp-LI in the electrically stimulated spinal cord}

In order to investigate whether newly recycled vesicles might take up D-Asp, we stimulated the axon tracts on one side of the spinal cord electrically $(20 \mathrm{~Hz}, 15 \mathrm{~min})$ after the axons had been loaded with D-Asp, and with D-Asp present in the incubation medium. Such electrical stimulation is known to cause a marked depletion in the clustered pool of synaptic vesicles (Wickelgren et al., 1985; O. Shupliakov, V. A. Pierbone, H. Gad, and L. Brodin, unpublished observations). A complete recovery of the vesicle cluster was observed after the period of rest $(30 \mathrm{~min})$. This manipulation did not cause the synaptic vesicle clusters to increase their content of D-Asp-LI relative to axoplasmic matrix (data not shown). 

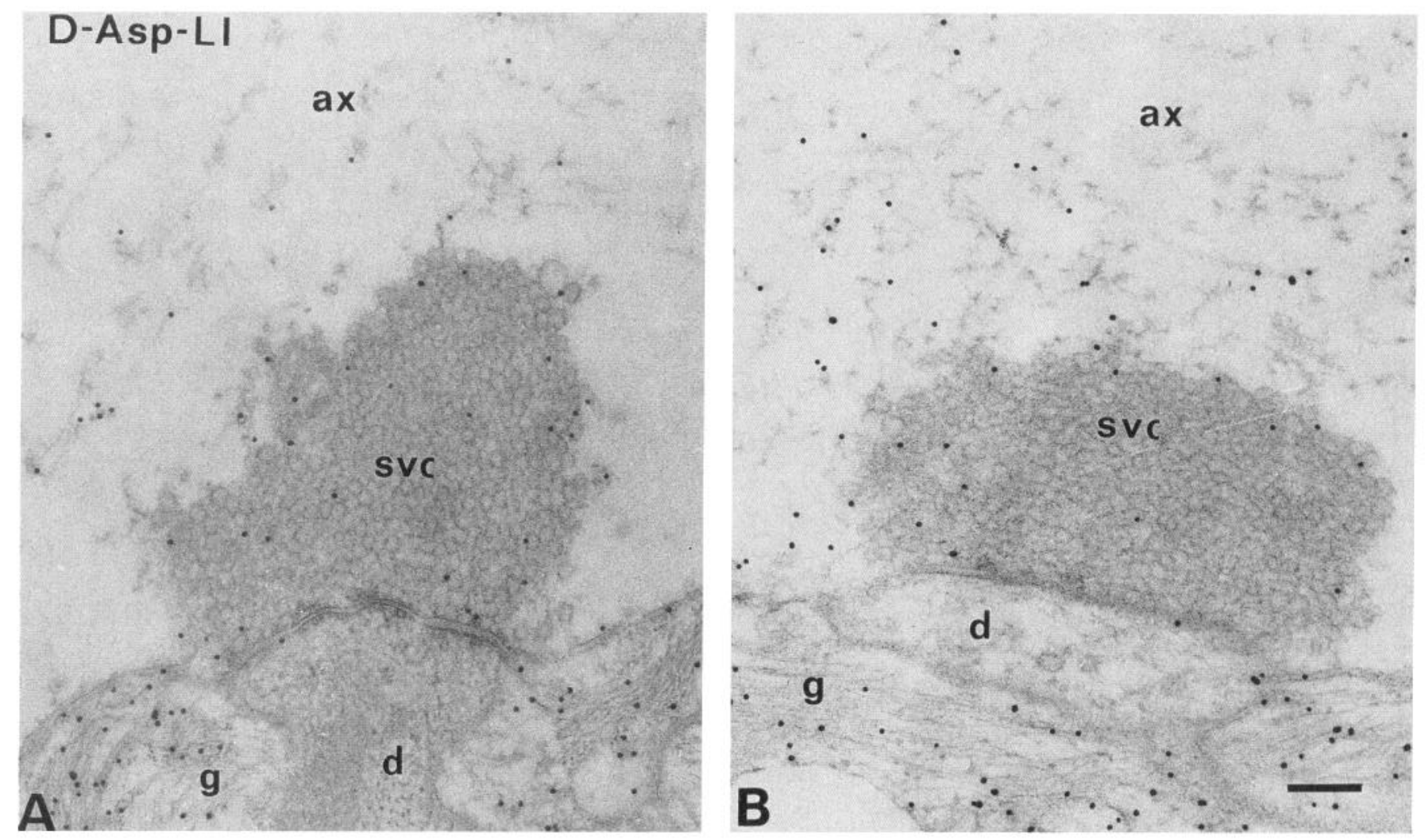

Figure 7. D-Aspartate-like immunoreactivity in reticulospinal synapses $(A)$ and dorsal column synapses $(B)$ and in their surrounding glial processes in tissue exposed to $500 \mu \mathrm{M}$ D-Asp for $10 \mathrm{hr}$. Note in $A$ the slight accumulation of labeling in the synaptic vesicle cluster (svc) compared to the axoplasmic matrix $(a x)$. Both postsynaptic dendrites $(d)$ are devoid of immunoreactivity, whereas glial processes $(g)$ contacting both synapses are enriched with gold particles. Scale bar, $0.2 \mu \mathrm{M}$.

\section{Discussion}

Validity of the present experimental approach

The present electron microscopical observations, in conjunction with previous electrophysiological studies (for review, see Brodin and Grillner, 1990), indicate that the isolated lamprey spinal cord preserves its integrity during prolonged incubation in vitro. (As lampreys normally live at temperatures down to $4^{\circ} \mathrm{C}$, most experiments on the isolated lamprey spinal cord are carried out at $5-10^{\circ} \mathrm{C}$. Synaptic and network activities are normal within this temperature interval.) Moreover, the fine structure of the synapses appeared to be unaffected by exposure to high concentrations of D-Asp, which correlates with the maintenance of synaptic transmission under similar conditions in this system (Brodin and Grillner, 1985; Brodin et al., 1985).

Model sections showed that the immunocytochemical signal was approximately proportional to the concentration of fixed D-Asp, and that even the higher D-Asp concentration used for incubation $(500 \mu \mathrm{M})$ is below the limit of detection. The observed immunogold signal therefore cannot be due to mere diffusion of the tracer through disrupted membranes. Together with the finding that the D-Asp antiserum produced no labeling of tissue not exposed to D-Asp, these observations show that the immunocytochemical signal represents D-Asp accumulated by membrane transport.

To what extent are the present data applicable to the mammalian brain? Clearly, the lamprey spinal cord exhibits some unusual features, such as the lack of myelin and blood vessels, and the presence of large unbranched axons. On the other hand, the physiological properties of the glutamatergic synaptic re- sponse, as well as the pharmacology of glutamate receptors and transporters, are strikingly similar to those in mammals (Brodin et al., 1985; Brodin and Grillner, 1985, 1990). We therefore find it reasonable to assume that the present data have implications for the function of the mammalian CNS (see also below).

\section{Glial processes take up Glu/Asp diffusely entering the extracellular space}

Bath application of D-Asp does not provide a model of synaptic Glu release, but rather mimics the diffuse efflux of Glu/Asp, which occurs during certain pathological conditions associated with Glu excitotoxicity (Croucher et al., 1982; Wieloch et al, 1985; Choi and Rothman, 1990; Mattson et al., 1990). For instance, during ischemia, excitatory amino acids appear to be lost from all parts of the neuron and accumulate in glial cells (Torp et al., 1993). (The reason why Glu is concentrated in glia under ischemic conditions could be that the conversion from Glu to glutamine by glutamine synthetase is inhibited due to lack of energy; under physiological conditions Glu is very low in glial cells (see Storm-Mathisen et al., 1992).) Our observation that exogenous D-Asp is predominantly taken up by glial processes suggests that astrocytes play the major role in curbing the extracellular level of Glu/Asp during such states.

Adding high concentrations of L-Glu, L-, or D-Asp to the medium produces little postsynaptic activation in the isolated spinal cord, unless the Glu/Asp uptake is suppressed (Brodin and Grillner, 1985). This observation and the present data suggest that the synaptic cleft may form a distinct compartment in terms of excitatory amino acid uptake, separate from that formed 

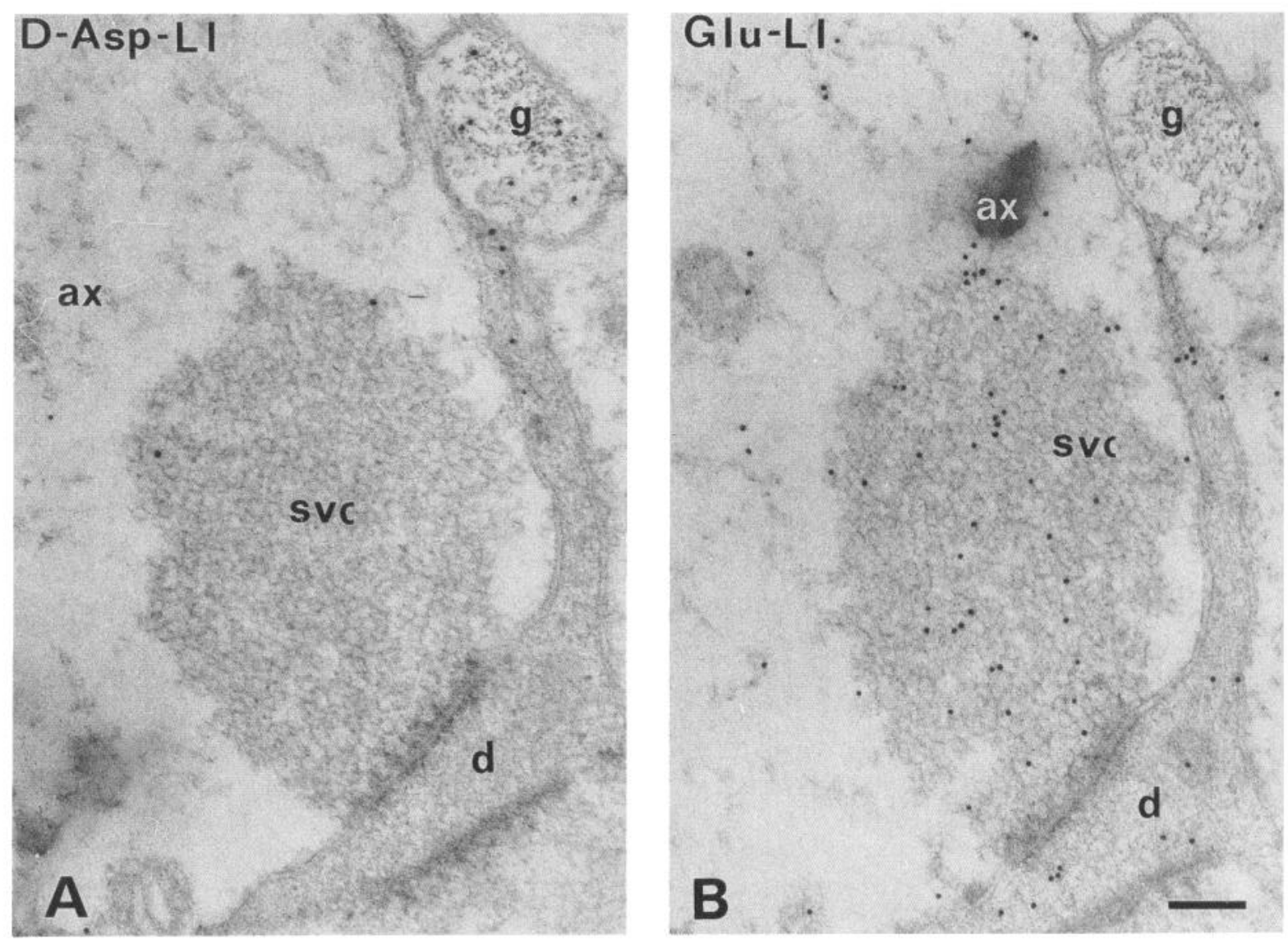

Figure 8. Electron micrographs of serial sections from tissue incubated with $500 \mu \mathrm{M}$ D-Asp for 10 hr showing the same dorsal column synapse labeled with D-Asp $(A)$ and Glu $(B)$ antibodies. In order to find the same synapse in adjacent sections, the sections were mounted on formvar coated grids. Since only one side was exposed to the antibodies, the particle density was lower as compared to that in the sections in Figure 7 . Glutamate-like immunoreactivity is strongly concentrated over synaptic vesicle clusters $(s v c)$ compared to axoplasmic matrix ( $a x$ ), whereas D-AspLI shows no accumulation. Note that the D-Asp antibodies produce enrichment of labeling over glial processes $(g)$ and that these profiles are unlabeled with the Glu antiserum. Postsynaptic dendrites $(d)$ are almost devoid of D-Asp-LI, but moderately Glu immunopositive. Scale bar, 0.2 $\mu \mathrm{m}$.

by the remaining extracellular space. The glial collar, which represents the boundary between these two compartments, may through its avid uptake limit the access of extrasynaptic Glu/ Asp to the synaptic cleft. This may explain why axonal labeling with exogenous D-Asp occurs only after long time incubation with high tracer concentrations, assuming that the transporters are within or near the active zones. Such an arrangement should ensure that the activation of the postsynaptic receptors is strongly biased toward synaptically released Glu. The glial collar would also be ideally suited to prevent movement of Glu in the opposite direction, from the synaptic to the extrasynaptic compartments of the extracellular space. In other words, the task of the glial collar is twofold: to impede access of extrasynaptic excitatory amino acids to the synaptic cleft and to take care of the synaptically released Glu that escapes uptake by presynaptic transporters. Glial processes also ensheath mammalian synapses (Peters et al., 1991), suggesting that the present data are relevant over a wide phylogenetical range. The glial ensheathment is poorly preserved in acute mammalian slice preparations, which exposes the neuronal transporters in nerve endings to higher exogenous tracer concentrations than in an intact preparation. This may explain why acute slices display a predominant nerve terminal uptake after exposure to exogenous tracers (Storm-
Mathisen and Iversen, 1979; Taxt and Storm-Mathisen, 1984; Gundersen et al., 1993).

Our results do not rule out the presence of a neuronal transporter in the lamprey spinal cord. On the contrary, there was labeling of axons after long-term incubation with high D-Asp concentrations. A previous investigation demonstrating retrograde transport of $\mathrm{D}^{-3} \mathrm{H}-\mathrm{Asp}$ in this preparation (Brodin et al., 1989) is in line with the idea that lamprey neurons possess uptake sites for Glu and Asp.

\section{Does glial uptake activity differ between synapses with} different firing patterns?

The present results indicate that uptake of excitatory amino acids is more efficient in the glial collar and processes surrounding the tonically active dorsal column synapses than in glial elements abutting on the phasically active reticulospinal axon synapses. This could imply that the glial uptake activity is tuned to the rate of transmitter release from the nearby synaptic sites and points to a novel regulatory role for Glu uptake.

The difference in labeling intensity between the two types of glial process could not be explained by differences in their surface to volume ratios (form factors) or filament protein contents. Nor could the difference be correlated to different distances of 


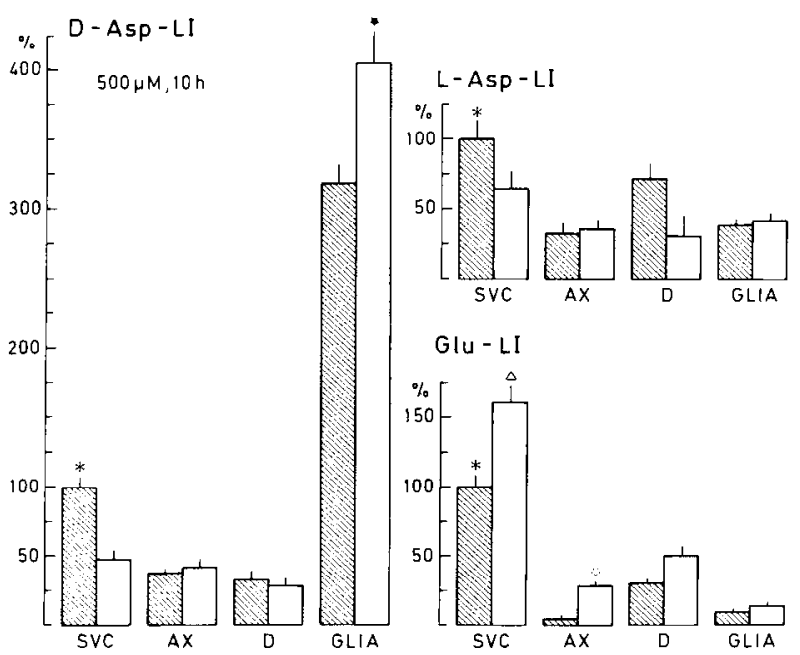

Figure 9. Quantitative determination of D-Asp-LI, L-Asp-LI, and Glu-LI in tissue compartments (see Fig. 6) in specimens exposed to 500 $\mu \mathrm{M}$ D-Asp for $10 \mathrm{hr}$. The values represent the mean \pm SEM expressed as percent of the mean number of D-Asp, L-Asp, and Glu immunogold particles $/ \mu \mathrm{m}^{2}$ over synaptic vesicle clusters in reticulospinal axons. Hatched columns and open columns represent various cellular and subcellular profiles related to reticulospinal axon synapses and dorsal column axon synapses, respectively. The values are pooled data ( $n$ tissue profiles) from three (D-Asp-LI) or two (Glu-LI and L-Asp-LI) immunocytochemical incubations. In the latter two incubations serial sections were exposed to D-Asp antibodies as well. The symbols represent significant differences in D-Asp-LI, L-Asp-LI, and Glu-LI between reticulospinal synaptic vesicle clusters $(n=31,10,16)$ and axoplasmic matrix $(n=29,10,16)$ (asterisks, $p<0.001)$, in Glu-LI between dorsal column vesicle clusters $(n=16)$ and axoplasmic matrix $(n=16)$ (triangle, $p<0.005)$, and between dorsal column axoplasmic matrix $(n=$ $16)$ and reticulospinal axoplasmic matrix $(n=16)$ (open star, $p<$ 0.005 ) and in D-Asp-LI between glial processes in contact with dorsal column synapses $(n=36)$ and glial processes around reticulospinal synapses $(n=34)$ (filled star, $p<0.001$ ). The D-Asp-LI value in dorsal column synaptic vesicle clusters $(n=32)$ is not significantly different from that in dorsal column axoplasmic matrix $(n=28), p=0.5$.

diffusion since the reticulospinal and dorsal column axons were at similar distance from the surface of the preparation (see Fig. 4).

The D-Asp transport across the glial cell membrane has not yet reached equilibrium by $1 \mathrm{hr}$, since the labeling intensity continued to increase up to $10 \mathrm{hr}$. This implies that the observed differences in D-Asp transport activity could either be due to different driving forces, or transporter subtypes with different kinetic properties, or a different density of transporter protein in the two types of glial processes.

The results of the simultaneous incubation with Tau and D-Asp, which utilize different plasma membrane carriers (Balcar and Johnston, 1972), suggest that a specific overexpression of excitatory amino acid transport in the dorsal column glia is superimposed on a generally high amino acid uptake activity in these cells.

\section{Is D-Asp accumulated in synaptic vesicles?}

Attempts to demonstrate Asp and Asp uptake in isolated synaptic vesicles have consistently failed (Naito and Ueda, 1983, 1985; Maycox et al., 1988; Burger et al., 1989, 1991; Fykse et al., 1992). However, it is conceivable that the isolation procedures cause the vesicles to lose their uptake activity for Asp, or that the proportion of Asp-ergic projections in the brain is too low for vesicular Asp uptake to be detected biochemically. In fact, the rapid retrograde transport of D- ${ }^{3} \mathrm{H}-\mathrm{Asp}$ (Baughman and Gilbert, 1980; Streit, 1980; Storm-Mathisen and Wold, 1981; Brodin et al., 1989) is suggestive of incorporation into synaptic vesicles or other organelles that are carried by the fast axonal transport system. It was therefore of interest to examine whether D-Asp is accumulated in synaptic vesicles in the intact synapse. According to the calibration curves, incubation with high concentrations of D-Asp at long times raised the nerve terminal concentration of D-Asp well above the $K_{m}$ value established for the Glu transporter in synaptic vesicles isolated from mammals and lower vertebrates (Tabb and Ueda, 1991). This notwithstanding, the modest enrichment of labeling observed over synaptic vesicle clusters was quite the same for D-Asp as for Tau and could therefore be explained by the higher fixation efficiency provided by higher protein contents. The findings that the relative enrichment of D-Asp-LI over synaptic vesicle clusters was more prominent in reticulospinal than in dorsal column axons can be explained in the same way (cf. Shupliakov et al., 1992). Further, the analysis of the electrically stimulated cord indicates that D-Asp does not gain access to the vesicles even during replenishment after synaptic release. Thus, we obtained no direct evidence for an active accumulation of $D-\Lambda$ sp in synaptic ves icles.

Neither was there any indirect evidence of D-Asp uptake in synaptic vesicles, since the high level of Glu immunolabeling in vesicle clusters was not decreased by exposure to D-Asp. This means that D-Asp does not replace vesicular Glu to an extent that can be detected by immunocytochemistry. The enrichment of Glu-LI over vesicle clusters further suggests that there is no general masking of antigenic sites in the vesicles.

The present data are in line with biochemical analyses of vesicular uptake and also agree with the reported failure to demonstrate exocytotic release of exogenous D-Asp from preloaded synaptosomes (McMahon and Nicholls, 1990). They further indicate that the high speed of retrograde D-Asp transport cannot be attributed to a sequestration of the tracer in vesicles (see Brodin et al., 1989). Rather, our findings point to mitochondria as possible vehicles for retrograde transport, at least in the lamprey spinal cord.

The failure of the vesicles to accumulate detectable amounts of D-Asp seems to parallel a failure to accumulate endogenous L-Asp, as judged from the low level of L-Asp immunolabeling over vesicle clusters. This confirms the findings of Shupliakov et al., 1992 [based on osmium-treated material that gives less efficient labeling of L-Asp (Zhang et al., 1993)]. Thus, Glu remains as the only likely transmitter in dorsal column and reticulospinal axon synapses.

We conclude that (1) glial uptake controls the level of excitatory amino acids in nonsynaptic parts of the extracellular space, suppressing diffusion of amino acids from this compartment into the synaptic cleft, (2) that the uptake activity in glial processes may be adjusted to the activity pattern of the nearby excitatory nerve endings, and (3) that D- (or L-)Asp does not gain access to synaptic vesicles in intact excitatory terminals in the lamprey spinal cord.

\section{References}

Amiry-Moghaddam M, Nagelhus E, Ottersen OP (1994) Light- and electron microscopic distribution of taurine, an organic osmolyte, in rat renal tubule cells. Kidney Int 45:10-22.

Balcar V, Johnston GAR (1972) The structural specificity of the high affinity uptake of L-glutamate and L-aspartate by rat brain slices. J Neurochem 19:2657-2666. 
Baughman RW, Gilbert CD (1980) Aspartate and glutamate as possible neurotransmitters of cells in layer 6 of the visual cortex. Nature 287: $848-850$.

Brodin L, Grillner S (1985) The role of putative excitatory amino acid neurotransmitters in the initiation of locomotion in the lamprey spinal cord. II. The effects of amino acid uptake inhibitors. Brain Res 360 : $149-158$.

Brodin L, Grillner S (1990) The lamprey CNS-an experimentally amenable model for studies of synaptic interactions and integrative functions. In: In vitro preparations from vertebrate CNS (Jahnsen $\mathrm{H}$, ed), pp 103-153. New York: Wiley.

Brodin L, Grillner S, Rovainen CM (1985) N-Methyl-D-aspartate (NMDA), kainate and quisqualate receptors and the generation of fictive locomotion in the lamprey spinal cord. Brain Res 325:302306.

Brodin L, Ohta Y, Hökfelt T, Grillner S (1989) Further evidence for excitatory amino acid transmission in lamprey reticulospinal neurons: selective retrograde labeling with ['H|D-aspartate. J Comp Neurol $281: 225-233$.

Burger PM, Mehl E, Cameron PL, Maycox PR, Baumert M, Lottspeich F, De Camilli P, Jahn R (1989) Synaptic vesicles immunoisolated from rat cerebral cortex contain high levels of glutamate. Neuron 3:715-720.

Burger PM, Hell J, Mehl E, Krasel C, Lottspeich F, Jahn R (1991) GABA and glycine in synaptic vesicles: storage and transport characteristics. Neuron 7:287-293.

Choi DW, Rothman SM (1990) The role of glutamate neurotoxicity in hypoxic-ischemic neuronal death. Annu Rev Neurosci 13:171-182.

Christensen H, Fykse EM, Fonnum F (1991) Inhibition of gammaaminobutyrate and glycine uptake into synaptic vesicles. Eur J Pharmacol 207:73-79.

Christenson J, Bohman A, Lagerbäck Å (1987a) The dorsal cell, one class of primary sensory neurone in the lamprey spinal cord. 1 . Touch, pressure, but no nociception-A physiological study. Brain Res 440: $1-8$.

Christenson J, Bohman A, Lagerbäck Å, Grillner S (1987b) The dorsal cell. one class of primary sensory neurone in the lamprey spinal cord. II. A light and electron microscopical study. Brain Res 440:9-17.

Croucher MJ, Collins JF, Meldrum BS (1982) Anticonvulsant action of excitatory amino acid antagonists. Science 216:899-901.

Dale N, Ottersen OP, Roberts A, Storm-Mathisen J (1986) Inhibitory neurones of a motor pattern generator in Xenopus revealed by antibodies to glycine. Nature 324:255-257.

Danbolt NC, Storm-Mathisen J, Kanner BI (1992) A $\left[\mathrm{Na}^{+}+\mathrm{K}^{+}\right]$coupled L-glutamate transporter purified from rat brain is located in glial cell processes. Neuroscience 51:295 310 .

Davanger S, Storm-Mathisen J, Ottersen OP (1994) Colocalization of glutamate and glycine in bipolar cell terminals of the human retina. Exp Brain Res 98:342-354.

Davies LP, Johnston GAR (1976) Uptake and release of D- and L-aspartate by rat brain slices. J Neurochem 26:1007-1014.

Fykse EM, Iversen EG, Fonnum F (1992) Inhibition of L-glutamate uptake into synaptic vesicles. Neurosci Lett 135:125-128.

Garthwaite G, Garthwaite J (1985) Sites of $D^{-}$I $^{3} \mathrm{H}$ |aspartate accumulation in mouse cerebellar slices. Brain Res 343:129-136.

Garthwaite G, Williams GD, Garthwaite J (1992) Glutamate toxicityan experimental and theoretical analysis. Eur J Neurosci 4:353-360.

Gundersen HJ, Bendtsen TF, Korbo L, Marcussen N, Møller A, Nielsen K, Nyengaard JR, Pakkenberg B, Sørensen FB, Vesterby A, West MJ (1988) Some new, simple and efficient stereological methods and their use in pathological research and diagnosis. APMIS 96:379-394.

Gundersen V, Danbolt NC, Ottersen OP, Storm-Mathisen J (1993) Demonstration of glutamate/aspartate uptake activity in nerve endings by use of antibodies recognizing exogenous D-aspartate. Neuroscience 57:97-111.

Hsu SM, Raine L, Fanger H (1981) Use of avidin-biotin-peroxidase complex $(\mathrm{ABC})$ in immunoperoxidase techniques: a comparison between $\mathrm{ABC}$ and unlabeled antibody (PAP) procedures. J Histochem Cytochem 29:577-580.

Ji Z, Aas JE, Laake J, Walberg F, Ottersen OP (1991) An electron microscopic, immunogold analysis of glutamate and glutamine in ter minals of rat spinocerebellar fibers. J Comp Neurol 307:296-310.

Kanai Y, Hediger MA (1992) Primary structure and functional characterization of a high-affinity glutamate transporter. Nature $360: 467-$ 471 .
Kanai Y, Smith CP, Hediger MA (1994) A new family of neurotransmitter transporters: the high-affinity glutamate transporters. FASEB J $8: 1450-1459$

Mattson MP (1990) Antigenic changes similar to those seen in neurofibrillary triangles are elicited by glutamate and $\mathrm{Ca}^{2}+$ influx in cultured hippocampal neurons. Neuron 2:105-117.

Maycox PR, Deckwerth T, Hell JW, Jahn R (1988) Glutamate uptake by brain synaptic vesicles. J Biol Chem 263:15423-15428.

McBean GJ, Roberts PJ (1984) Neurotoxicity of I-glutamate and DLthreo-3-hydroxyasparate in the rat striatum. J Neurochem 44:247254.

McMahon HT, Nicholls DG (1990) Glutamine and aspartate loading of synaptosomes: a reevaluation of effects on calcium-dependent excitatory amino acid release. J Neurochem 54:373-380.

Naito S, Ueda T (1983) Adenosine triphosphate-dependent uptake of glutamate into protein I-associated synaptic vesicles. J Biol Chem 258:696-699.

Naito S, Ueda T (1985) Characterization of glutamate uptake into synaptic vesicles. J Neurochem 44:99-109.

Nicholls DG (1989) Release of glutamate, aspartate, and $\gamma$-aminobutyric acid from isolated nerve teminals. J Neurochem 52:331-341.

Ottersen OP (1987) Postembedding light- and electron microscopic immunocytochemistry of amino acids: description of a new model system allowing identical conditions for specificity testing and tissue processing. Exp Brain Res 69:167-174.

Ottersen OP (1989) Quantitative electron microscopic immunocytochemistry of amino acids. Anat Embryol 180:1-15.

Peters A, Palay SL, Webster HF (1991) The tine structure of the nervous system: neurons and their supporting cells. New York: Oxford UP.

Shupliakov O, Brodin L, Cullheim S, Ottersen OP. Storm-Mathisen J (1992) Immunogold quantification of glutamate in two types of excitatory synapse with different firing patterns. J Neurosci 12:37893803.

Shupliakov O, Brodin L, Srinivasan M, Grillner S, Cullheim S, StormMathisen J, Ottersen OP (1994) Extrasynaptic localization of taurine-like immunoreactivity in the lamprey spinal cord. J Comp Neurol 347:301-311.

Somogyi P, Halasy K, Somogyi J, Storm-Mathisen J, Ottersen OP (1986) Quantification of immunogold labelling reveals enrichment of glutamate in mossy and parallel fibre terminals in cat cerebellum. Neuroscience 19:1045-1050.

Storck T, Schulte S, Hofmann K, Stoffel W (1992) Structure, expression, and functional analysis of a $\mathrm{Na}\left({ }^{+}\right)$-dependent glutamate/aspartate transporter from rat brain. Proc Natl Acad Sci USA 89:10955 10959.

Storm-Mathisen J, Iversen LL (1979) Uptake of ['H]glutamic acid in excitatory nerve endings: light and electron microscopic observations in the hippocampal formation of the rat. Neuroscience $4: 1237-1253$.

Storm-Mathisen J, Ottersen OP (1990) Immunocytochemistry of glutamate at the synaptic level. J Histochem Cytochem 38:1733 1743.

Storm-Mathisen J, Wold JE (1981) In vivo high-affinity uptake and axonal transport of $\mathrm{D}-\left[2,3-{ }^{3} \mathrm{H}\right]$ aspartate in excitatory neurons. Brain Res 230:427-433.

Storm-Mathisen J, Leknes AK, Bore A, Vaaland JL, Edminson P, Haug FMS, Ottersen OP (1983) First visualization of glutamate and GABA in neurones by immunocytochemistry. Nature 301:517-520.

Storm-Mathisen J, Danbolt NC, Rothe F, Torp R, Zhang N, Aas JE, Kanner BI, I angmoen I, Ottersen OP (1992) Ultrastructural immunocytochemical observations on the localization, metabolism and transport of glutamate in normal and ischemic brain tissue. Prog Brain Res 94:225-241.

Streit $P$ (1980) Selective retrograde labeling indicating the transmitter of neuronal pathways. J Comp Neurol 191:429-463.

Tabb JS , Ueda T (1991) Phylogenetic studies of the synaptic vesicle glutamate transport system. J Neurosci 11:1822-1828.

Taxt T, Storm-Mathisen J (1984) Uptake of D-aspartate and I-glutamate in excitatory axon terminals in hippocampus: autoradiographic and biochemical comparison with gamma-aminobutyrate and other amino acids in normal rats and in rats with lesions. Neuroscience 11:79100.

Torp R, Arvin B, Le Peillet E, Chapman AG, Ottersen OP, Meldrum BS (1993) Effect of ischemia and reperfusion on the extra- and intracellular distribution of glutamate, glutamine, aspartate and 
GABA in the rat hippocampus, with a note on the effect of the sodium channel blocker BW I003C 8\%. Exp Brain Res 96:365-376.

Wickelgren WO, Leonard JP, Grimes MJ, Clark RD (1985) Ultrastructural correlates to transmitter release in presynaptic areas of lamprey reticulospinal axons. J Neurosci 5:1188-1201.

Wieloch $T$ (1985) Hypoglycemia-induced neuronal damage prevented by an $N$-methyl-D-aspartate antagonist. Science 230:681-683.

Wilkin GP. Garthwaite J, Balázs R (1982) Putative acidic amino acid transmitters in the cerebellum. II. Electron microscopic localization of transport sites. Brain Res 214:69-80.
Zhang N, Ottersen OP (1992) Differential cellular distribution of two sulphur-containing amino acids in rat cerebellum. An immunocytochemical investigation using antisera to taurine and homocysteic acid. Exp Brain Res 90:11-20.

Zhang N, Storm-Mathisen J, Ottersen OP (1993) A model system for specificity testing and antigen quantitation in single and double labelling postembedding electron microscopic immunocytochemistry. Neurosci Protocols 93-050-13:1-20. 